\title{
Analysis of the Behaviour of Very Slender Piles: Focus on the Ultimate Load
}

\author{
Michele Placido Antonio Gatto ${ }^{1} \cdot$ Lorella Montrasio $^{1}$
}

Received: 9 December 2019 / Revised: 10 June 2020 / Accepted: 9 July 2020 / Published online: 27 August 2020

(c) The Author(s) 2020

\begin{abstract}
The paper aims to analyse the influence of slenderness on the ultimate behaviour of piles with a very small diameter (less than $10 \mathrm{~cm}$ ) that are often employed in soil reinforcement and for which the slenderness can significatively influence the failure behaviour, reducing the ultimate load. The aim is reached by means of numerical analyses on small-diameter piles of different geometries, embedded in clayey soil. The critical load is evaluated numerically in undrained conditions and then compared to the bearing capacity estimated by the classical approaches based on limit equilibrium method. The numerical model is first calibrated on the basis of the results of experimental laboratory tests on bored piles of a small diameter in a cohesive soft soil (average undrained shear strength $c_{u}=15 \mathrm{kPa}$ ). The comparison between the critical load and the bearing capacity shows that their ratio becomes less than 1 for critical slenderness $L_{\mathrm{CR}}$ that decreases, nonlinearly, with the decreasing of the pile diameter. The results of the analysis show that varying the diameter of the pile from 0.06 to $0.18 \mathrm{~m}$, $L_{\mathrm{CR}}$ varies from 65 to 200. The aforementioned evidence suggests that the evaluation of the ultimate load of piles of very small diameter has to follow the considerations on the critical load of the pile, especially if it is embedded in soft soil; on the contrary for piles of greater diameters (bigger than $20 \mathrm{~cm}$ ) the buckling is not meaningful because $L_{\mathrm{CR}}$ is so big that the common slenderness does not exceed it.
\end{abstract}

Keywords Slender piles $\cdot$ Buckling $\cdot$ Ultimate load $\cdot$ FE analysis $\cdot$ Pile-soil interface

\section{Introduction}

Buildings founded on soil of poor properties may experience excessive settlements or give rise to the failure of soil, due to its low bearing capacity; the soil improvement techniques are finalised to reduce these phenomena. These techniques can be grouped into interventions based on soil replacement [1] or providing reinforcement in different ways, such as sand compaction piles [2], stone columns for slope stability [3] or lightweight fill [4], through sawdust, tire-derived aggregate and geofoam, for consolidation and differential settlements minimisation. Among the soil reinforcement methods, a common solution is based on the use of micropiles [5, 6]; case studies and numerical simulations have

Lorella Montrasio

lorella.montrasio@unipr.it

Michele Placido Antonio Gatto

micheleplacidoantonio.gatto@unipr.it

1 Department of Engineering and Architecture, University of Parma, 43124 Parma, Italy demonstrated the increase of the soil stiffness and bearing capacity due to the use of micropiles [7-11].

"Most micropiles are 100-250 mm in diameter, 20-30 m long" [6]: due to their small diameter $d$, when micropiles of considerable length $L$ are axially loaded, they may experience the buckling phenomenon, due to very high slenderness $L / d$, ranging from 80 to 300 . In recent years, micropiles driven into soil are widespread; the driven pressure is related to the bearing capacity $Q_{\lim }$ and this sometimes allows to reach considerable length. In such a way, very slender piles are axially loaded in order to be driven into the soil and it is not so obvious that the ultimate conditions are reached for bearing capacity loss: because of high slenderness, they can indeed buckle. The paper tries to investigate how slenderness affects the ultimate conditions; in other words, we are trying to understand for which slenderness we need to consider the pile bearing capacity or the buckling load as the ultimate.

The buckling load of a structural element embedded in the soil is referred to as the critical load $P_{\mathrm{CR}}$. It is not exactly the Eulero's load $P_{\mathrm{EU}}$, i.e. the buckling load of 
a rod axially loaded; thanks to the soil lateral support, the $P_{\mathrm{CR}}$ is greater than $P_{\mathrm{EU}}$. So, for which soil should we worry about the buckling of piles? Initially, some authors [12-14] stated that the soil lateral support, even if weak, is sufficient to prevent buckling; also the International Building Code states that "any soil other than fluid soil shall be deemed to afford sufficient lateral support to the pier or pile to prevent buckling". However, a specific attention to the problem must be paid for weak soils, which give rise to poor lateral confinement, and the $P_{\mathrm{CR}}$ may become closer to $P_{\mathrm{EU}}$. The Massachusetts building code provides protection against buckling by reducing the design yielding stress [15] for piles embedded in very soft soil [16]. The European Standard EN 1997-1 [17] generally refers to the necessity of buckling assessment for soils of undrained shear strength $c_{u}<10 \mathrm{kN} / \mathrm{m}^{2}$, while German DIN 1054 [18] requires a specific buckling assessment for slender piles in cohesive soils of undrained shear strength $c_{u}<15 \mathrm{kN} / \mathrm{m}^{2}$. The soil type to which the paper is addressed is therefore a normally consolidated clay, which provides weak confinement. It is important to state that building codes discuss slender piles which rarely overcome a 130 length/diameter ratio (typical of commonly employed piles); micropiles, the object of this paper, could reach even greater slenderness.

How can we evaluate $P_{\mathrm{CR}}$ ? Semi-empirical formulae have been provided based on full-scale load tests considering soil schematised into springs [19-21]; other literature analytical formulations model the soil contribution with a subgrade reaction modulus and consequently a spring approach [22-28]. In all these cases, buckling has been mainly studied for piles, in general; only a few literature examples reserve specific attention to the case of micropiles $[29,30]$. However, a spring approach may be not suitable to accurately model the lateral support of the soil. Thus, the paper introduces a specific finite element model able to evaluate the critical load. For the numerical modelling, a two-dimensional plane-strain model is chosen for the soil with an elastic perfectly plastic material; a pile-soil frictional contact is also introduced, which strongly affects the lateral displacement of the pile. Dealing with the modelling of a single pile, this numerical assumption may be considered acceptable, if the interface parameters are suitably calibrated; this is done on the basis of load-horizontal displacement curves found in the literature, of large-scale load tests performed at the Geotechnical Centre of the Technical University of Munich on piles embedded in soft clay [31, 32]. Once the model is calibrated, it is applied for the evaluation of the $P_{\mathrm{CR}}$ in different pile geometries and slenderness; the critical loads are therefore compared to the $Q_{\text {lim }}$ values, derived through the classical formula of bearing capacity of deep foundations on soft clay, in order to establish how the slenderness affects the ultimate behaviour.

\section{A Finite Element Model for $\boldsymbol{P}_{\mathrm{CR}}$ Evaluation}

In this section the numerical model used for the evaluation of the critical load for slender pile embedded in soft clay is proposed. After the general description of the model, the large-scale experimental results used for the model validation and calibration are presented. The material parameters selection is shown, and in the last subsection, a comparison of numerical-experimental results is illustrated.

\subsection{Description of the Numerical Model}

A commercial finite element software ADINA [33] is used to model the behaviour of micropiles axially loaded. The pile is meshed through 2-node beam elements of linear elastic material; the software requires the introduction of the cross-sectional area and the moment of inertia for these elements, so that piles with different cross sections can be considered.

For the soil, 9-node quadrangular elements in plane-strain conditions are used, with a mesh more discretised close to the pile, where accurate information is required. Literature examples show that a plane-strain modelling for the soil in problems of piles axially loaded provides a stiffer confinement (numerical displacements smaller than the experimental reality), but the deflection profile is well captured [34, 35]. A modified Mohr-Coulomb criterion is used to model the soil's constitutive behaviour. At its boundaries, the soil is pinned horizontally in order to avoid outward movement; the vertical degree of freedom is allowed for the development of the geostatic stress.

Static analyses are performed through an automatic time stepping (ATS) scheme; large displacements and small deformations are considered as kinematic assumptions. Loads are applied in two main phases: in the first phase, the soil's self-weight is applied gradually; in the second phase, the pile head is axially loaded with an incremental axial force. A target node is chosen on the pile, half-way up, where the vertical load and the horizontal displacements are read; the critical load is associated with a horizontal asymptote in the load-displacement curve.

One of the factors mainly influencing the numerical results of a pile-soil interaction problem is the interface; a "constraint function algorithm" is used [36]: two (or more) surfaces are coupled, giving rise to a frictional contact governed by the friction coefficient $\mu$. The normal and tangential contact forces are smoothed out with the distance from the contact according to two "modeldependent" parameters, respectively, $\varepsilon_{N}$ and $\varepsilon_{T}$; the latter also controls the switch of the contact nodes from stick to 
slip condition. Finally, the compliance factor CF allows to artificially soften the contact surfaces and help the convergence. In the following, the calibration of the numerical model with a proper choice of the material, as well as the interface parameters, is shown, based on experimental results found in the literature; this is essential to evaluate the quality of the numerical modelling.

\subsection{Calibration and Validation of the Numerical Modelling}

\subsubsection{Description of the Experimental Tests Used for the Numerical Model Validation}

In the literature, there are different examples of experimental tests performed on pile foundations for different purposes $[37,38]$; the results of an experimental campaign consisting of axial load tests on model piles performed at the Geotechnical Centre of the Technical University of Munich [31,32] are used for the validation of the FE model. A large-scale model has been set up consisting of a cylindrical container, which the pile is pinned to (Fig. 1a). Authors consider two pile types, in both cases $4 \mathrm{~m}$ long: Type I with circular concrete-steel composite section $(d=100 \mathrm{~mm}, L / d=40)$ and Type II with a rectangular aluminium section $(40 \times 100 \mathrm{~mm}$, $L / d \sim 100$ ).

As reported in introduction, according to most building codes, buckling is likely to happen in slender piles when embedded in weak soils of poor properties; the plastic China clay (liquid limit $w_{L}=55 \%$, plastic limit $w_{P}=28 \%$ and plasticity index $I_{P}=27 \%$, unit weight $\gamma_{\text {sat }}=19 \mathrm{kN} / \mathrm{m}^{3}$, friction angle $\varphi^{\prime}=25^{\circ}$ ) was used and pumped inside the container (Fig. 1b). The clay was first preconsolidated using dead loads; then, its consolidation process was accelerated by means of electro-osmosis and geotextile vertical drains; the undrained shear strength $c_{u}$ was measured through vane tests, performed at different depths in the soil inside the experimental container, revealing a linear increase with depth. The authors have assumed a mean $c_{u}$ value equal to $15 \mathrm{kN} / \mathrm{m}^{2}$; this value represents the upper limit under which buckling assessment is required according to DIN 1054.

Different axial loads have been applied to the pile head; for each load, the lateral displacements have been measured thanks to displacement transducers placed every metre in depth (Fig. 1c). In the paper, along with the experimental tests available from Vogt et al., the results of tests performed on pile Type II are considered, because aluminium shows

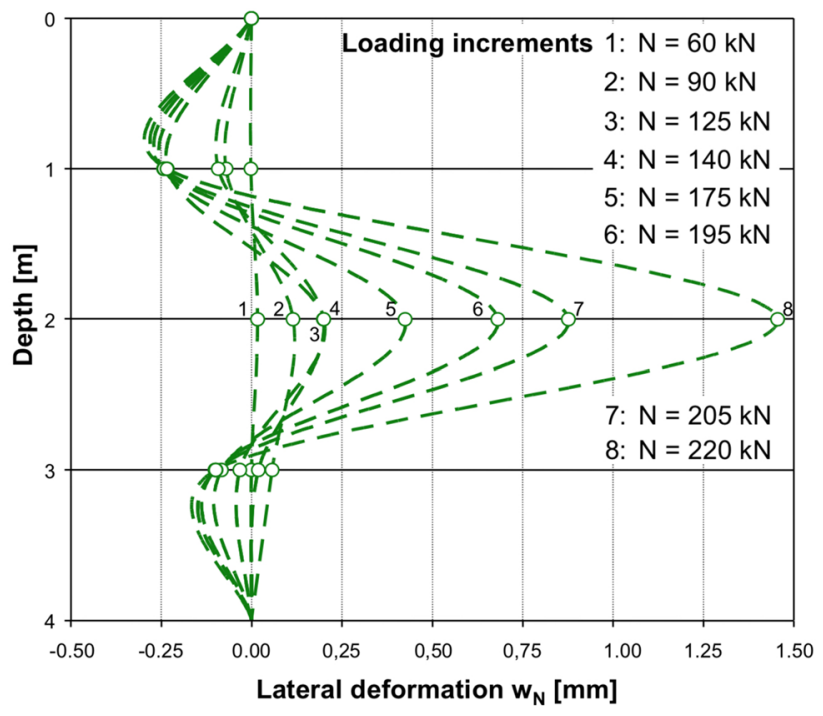

Fig. 2 Experimental measurements of lateral displacements on Type II piles $(40 \times 100 \mathrm{~mm})$ after Vogt et al. [31, 32]
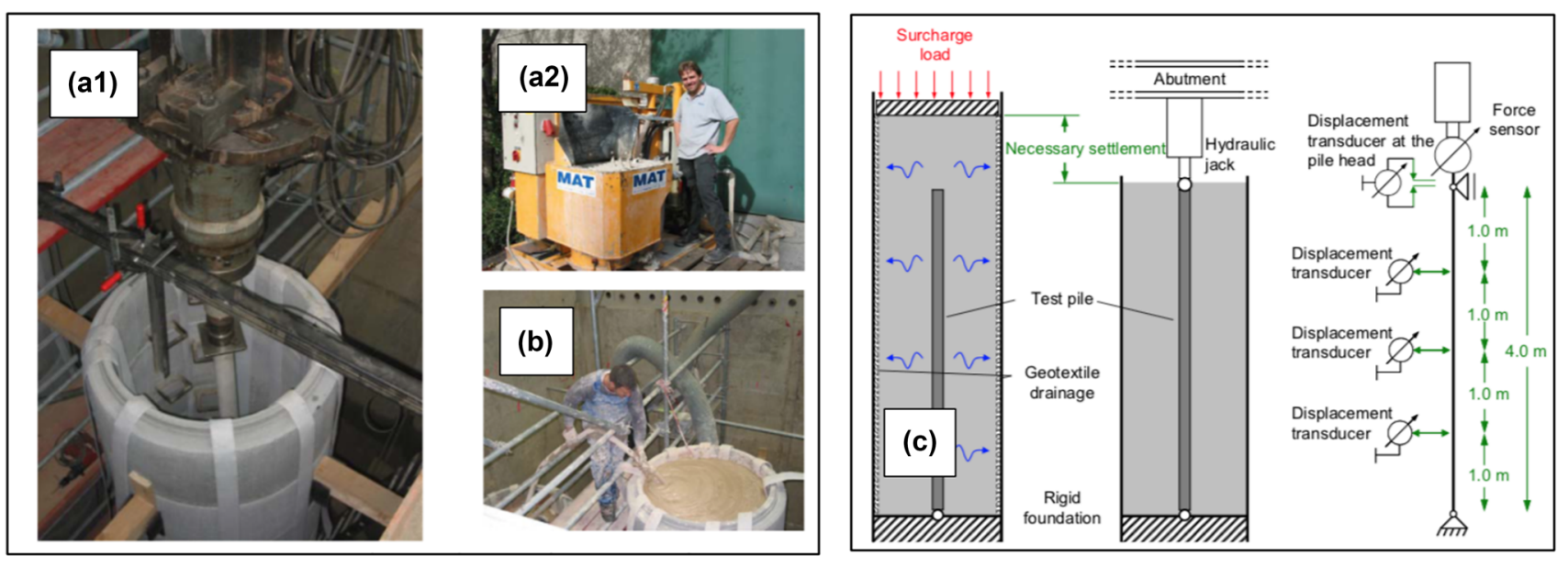

Fig. 1 Experimental system located at the Geotechnical Centre of the Technical University of Munich, after Vogt et al. [31, 32]. a1 and a2 Test apparatus; b liquid clay pumping; c experimental system scheme 
fewer uncertainties related to material characteristics; the lateral displacements for different axial loads $N$ related to this pile type are illustrated in Fig. 2. Authors have revealed that the pile failure occurs at $N=220 \mathrm{kN}$, with any noticeable plastic deformations; in this case, the ultimate load has therefore been linked to the loss of stability and it deals with a critical load $P_{\mathrm{CR}}$. Figure 2 shows us that the maximum horizontal displacement for each applied axial load is recorded at the middle of pile's length; the experimental displacements recorded at this point will be compared to the numerical results.

\subsubsection{Definition of Material and Interface Parameters for the Numerical Simulation of the Experimental Results}

The FE model described in Sect. 2.1 is now used to numerically simulate the experimental tests. For the pile, a rectangular cross section $40 \times 100 \mathrm{~mm}^{2}$ is put into the beam element; Young's modulus $E=64,000 \mathrm{MPa}$ is used for the aluminium section. The pile ends are pinned horizontally, in coherence with the experimentation.

The soil modelling is crucial because the horizontal displacements of the pile and its lateral stability, in general, depend on it, together with a proper modelling of the pile-soil interface. According to the constitutive law adopted (modified Mohr-Coulomb's model), the soil confinement is given by Young's modulus; values of the undrained modulus $E_{u}$ are derived from the undrained shear strength $c_{u}$ measured in the experimental tests. A soft clay with a plasticity index lower than $30 \%$ shows $E_{u} / c_{u}$ ranging from 600 to 5000 ([39]; Bowles, 1988 in [40]). For $I_{p}=27 \%$ the value of 800 is chosen; considering the soil modulus decay, this value is usually associated with a great strain level, of approximately $0.05-0.1 \%$ [40], compatible with the maximum strain of this experimentation.

As reported in the previous paragraph, the experimental $c_{u}$ was noticed to increase linearly with depth $\left(c_{u}=15 \mathrm{kPa}\right.$ is a mean value); a variation of $c_{u}$ with depth wants to be introduced into the model. According to the soil type, the ratio $\frac{c_{u}}{\sigma^{\prime}{ }_{\nu 0}}$ is constant, the effective vertical stress being $\sigma_{\nu 0}^{\prime}$ [41]; in the case presented, at a middle point $\sigma_{\nu 0}^{\prime}=18 \mathrm{kPa}$ and consequently $=\frac{c_{u}}{\sigma^{\prime}{ }_{v 0}} 0.83$ (this value appears to be coherent with values reported in [41]). Evaluating $\sigma^{\prime}{ }_{\nu 0}$ at different depths, a $c_{u}$ value corresponding to this depth can be calculated, so introducing a linear variation with depth; being $E_{u}$ depending on $c_{u}$, a variation of Young's modulus is consequently considered. In the numerical model the soil surface is therefore divided into eight layers (Fig. 3) and a mean value is assumed for each layer. Table 1 contains the values adopted, corresponding to the mean depth $z$ of each layer.

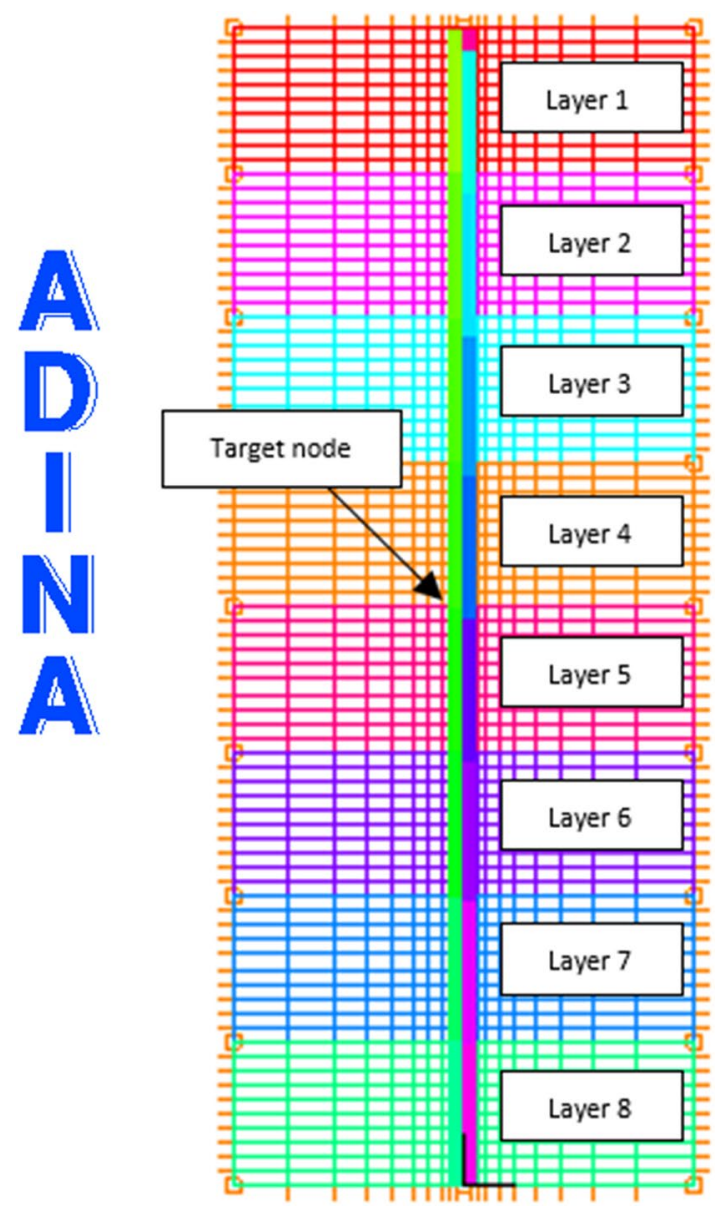

Fig. 3 Adopted numerical 2D plane-strain model

Table 1 Soil parameter evaluation for each layer of the numerical analysis

\begin{tabular}{lcccc}
\hline Layer & $z(\mathrm{~m})$ & $\sigma^{\prime}{ }_{v 0}=\gamma^{\prime} z(\mathrm{kPa})$ & \multicolumn{2}{c}{$c_{u}=0.83 \sigma^{\prime}{ }_{\nu 0} E_{u}=800 c_{u}(\mathrm{kPa})$} \\
\hline 1 & 0.125 & 1.1 & 0.93 & 747 \\
2 & 0.375 & 3.4 & 2.80 & 2241 \\
3 & 0.625 & 5.6 & 4.67 & 3735 \\
4 & 0.875 & 7.9 & 6.54 & 5229 \\
5 & 1.125 & 10.1 & 8.40 & 6723 \\
6 & 1.375 & 12.4 & 10.27 & 8217 \\
7 & 1.625 & 14.6 & 12.14 & 9711 \\
8 & 1.875 & 16.9 & 14.01 & 11,205 \\
\hline
\end{tabular}

Other than the material parameter choice, the section's aim is also the calibration of the numerical interface parameters so that the model could capture the experimental $P_{\mathrm{CR}}$. The friction coefficient $\mu$ is set to 0.36 , assuming an angle of friction soil-pile of $20^{\circ}$; different values of $\varepsilon_{N}$, 
$\varepsilon_{T}$ and $\mathrm{CF}$ are analysed, in order to study their influence on the $P_{\mathrm{CR}}\left(\varepsilon_{N}=10^{-15} \div 10^{-7}, \varepsilon_{\mathrm{T}}=10^{-7} \div 1, \mathrm{CF}=10^{-7} \div 10^{-2}\right)$.

\subsubsection{Numerical vs Experimental Results}

The numerical outputs are the loads and the horizontal displacements in the target node; the buckling load is reached when a horizontal asymptote is observed in the load-displacement curve. The values of $P_{\mathrm{CR}}$ by changing the interface parameters are reported in Fig. 4 . It is evident that $\varepsilon_{N}$ and $\varepsilon_{T}$ do not affect the critical load value: they represent a sort of normal/tangential contact stiffness, which influences only the magnitude of lateral displacement. On the other hand, CF strongly affects the $P_{\mathrm{CR}}$ : values less than or equal to $10^{-5}$ determine a stable FE critical load. $\varepsilon_{N}=10^{-12}$, $\varepsilon_{T}=10^{-3}$ and $\mathrm{CF}=10^{-5}$ are finally assumed.

In order to evaluate the accuracy of the calibration in relation to the critical load, Fig. 5 shows an experimental-numerical comparison of the load-displacement curve in the target node, which corresponds to the point where maximum displacements are recorded experimentally; it is observed how the numerical model is able to capture the experimental critical load with only $18 \%$ of difference, which is considered much more than reasonable. In the following, the application of the numerical model is therefore extended to a parametric study, focusing on the influence of slenderness $L / d$ on the ultimate behaviour of piles of different geometries.

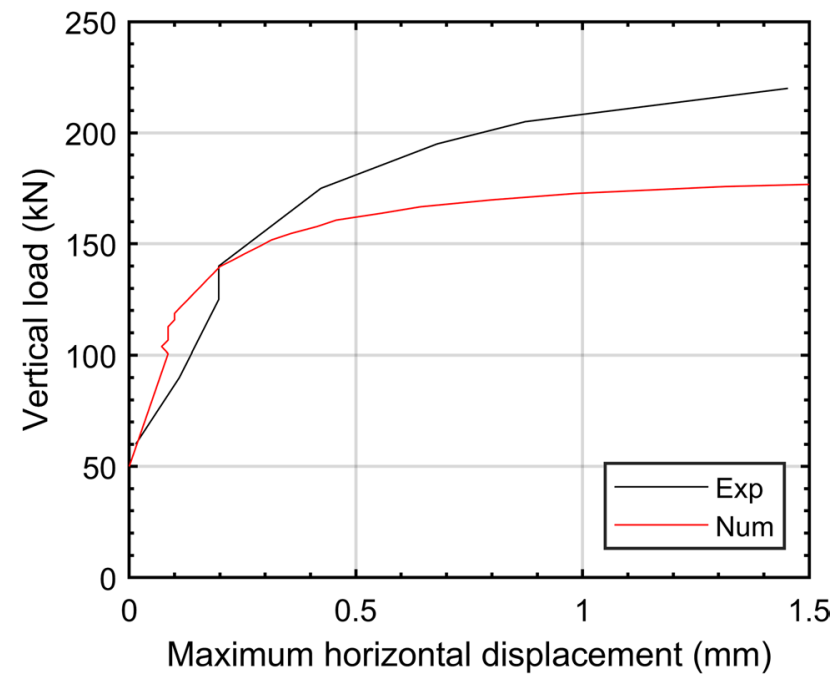

Fig. 5 Comparison of experimental-numerical vertical loads-horizontal displacements in the target node

\section{Slenderness Influence on the Ultimate Behaviour of Micropiles-A Parametric Analysis}

The numerical model, whose calibration was described in the previous paragraph, is now extended to a parametric analysis. Steel tubular piles (thickness $0.008 \mathrm{~m}$ ) of three different diameters are considered: $d=0.06,0.12$ and $0.18 \mathrm{~m}$; pile lengths
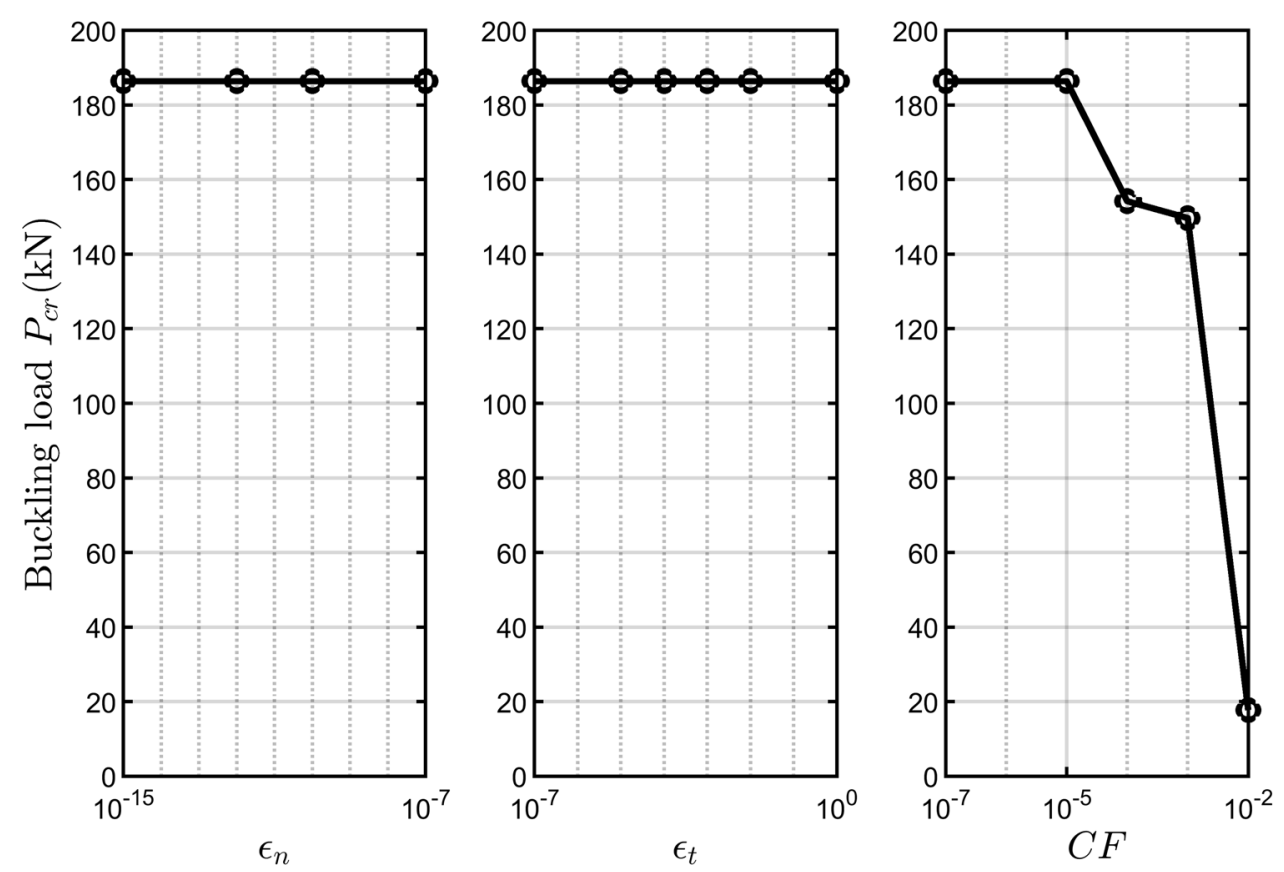

Fig. 4 Effects of the interface parameters on the numerical $P_{\mathrm{CR}}$ 
vary between 2 and $60 \mathrm{~m}$, so that different slenderness $L / d$ can be considered, ranging between 33 and 250 for all diameters. In these analyses, the pile's head is free but fixed at the base. The soil type considered is the same as the previous analyses; numerically, even in this case the soil surface is divided into eight layers. Starting from $\frac{c_{u}}{\sigma^{\prime}{ }^{\prime} 0}=0.83$, experimentally obtained, for each length under consideration the undrained shear strength will change. By assuming the plasticity index of the China clay, the ratio $E_{l} / c_{u}$ is equal to 800; according to $c_{u}$, different Young's moduli may be assumed for each pile's length. An example of the parameter evaluation for three different lengths is reported in Table 2.

With these material parameters, the numerical model is used to evaluate the FE critical load $P_{\mathrm{CR}}$; the value is compared to the bearing capacity $Q_{\text {lim }}$ relating to each geometry, in order to define an ultimate load, as the minor between $P_{\mathrm{CR}}$ and $Q_{\text {lim }}$ for the slenderness under consideration. In other words, it is investigated whether there is a threshold above which the pile ceases to behave as "a pile" (i.e. the behaviour governed by the bearing capacity) and the buckling effects predominate.

\subsection{Evaluation of the Pile Bearing Capacity}

The bearing capacity $Q_{\text {lim }}$ is the sum of two contributions: the end bearing capacity $P$ and the skin friction $S$, according to the classical formula for bearing capacity:

$Q_{\lim }=P+S=\frac{\pi d^{2}}{4} p+\int_{0}^{L} s \cdot d z$

$p$ is the unit base resistance; for cohesive soils in undrained conditions, it is commonly evaluated through Terzaghi's bearing capacity equation as:

$p=N_{c} \cdot c_{u}+\sigma_{v L}$,

$N_{c}$ is a bearing capacity factor equal to 9 in the case of piles [42]; $\sigma_{v L}$ represents the total vertical stress at the pile length depth. It is sometimes neglected because it compensates the pile weight [43].

$s$ represents a shaft resistance; in the literature there is a wide variety of approaches for its evaluation [43-45]; the most popular considers its estimation related to the undrained shear strength (total stress approach) as:

$s=\alpha c_{u}$,

$\alpha$ is an adhesion factor; even in this case, different expressions are found in the literature for its computation [46, 47]. The American Petroleum Institute (API) recommendation (1987) is used in this case, according to which:

$\alpha= \begin{cases}1 & \text { for } c_{u} \leq 25 \mathrm{kPa} \\ 1-\frac{c_{u}-25}{90} & \text { for } 25<c_{u}<70 \mathrm{kPa} . \\ 0.5 & \text { for } c_{u} \geq 70 \mathrm{kPa}\end{cases}$

Table 3 shows the unit base and shaft resistances, evaluated through Eqs. (2-4) for the lengths in consideration; $\sigma^{\prime}{ }_{v 0}$ is evaluated at the middle of the pile's length.

\subsection{Comparison Bearing Capacity-Critical Loads for Different Geometries}

Figure 6 illustrates the comparison between the critical load and the bearing capacity varying with slenderness, at the three diameters in consideration; the ultimate load is represented in bold. It is noticeable that the ultimate behaviour is not always depending on the bearing capacity; in piles of diameter $0.06 \mathrm{~m}$, for example, the ultimate load is governed by the critical load for slenderness about 65 .

A critical slenderness is therefore observed to control the failure mode; its values are reported in Fig. 7a for the diameters investigated. A critical length can be associated with each critical slenderness and is reported in Fig. 7b. A nonlinear dependence of the slenderness threshold on the

Table 2 Example of soil Young's moduli evaluation for three different pile lengths

\begin{tabular}{|c|c|c|c|c|c|c|c|c|c|}
\hline \multirow[t]{2}{*}{ Layer } & \multicolumn{3}{|c|}{$L=8 \mathrm{~m}$} & \multicolumn{3}{|c|}{$L=15 \mathrm{~m}$} & \multicolumn{3}{|c|}{$L=30 \mathrm{~m}$} \\
\hline & $z(\mathrm{~m})$ & $\sigma_{\nu 0}^{\prime}(\mathrm{kPa})$ & $E_{u}(\mathrm{kPa})$ & $z(\mathrm{~m})$ & $\sigma_{\nu 0}^{\prime}(\mathrm{kPa})$ & $E_{u}(\mathrm{kPa})$ & $z(\mathrm{~m})$ & $\sigma_{\nu 0}^{\prime}(\mathrm{kPa})$ & $E_{u}(\mathrm{kPa})$ \\
\hline 1 & 0.500 & 4.5 & 2988 & 0.938 & 8.4 & 5603 & 1.875 & 16.9 & 11,205 \\
\hline 2 & 1.500 & 13.5 & 8964 & 2.813 & 25.3 & 16,808 & 5.625 & 50.6 & 33,615 \\
\hline 3 & 2.500 & 22.5 & 14,940 & 4.688 & 42.2 & 28,013 & 9.375 & 84.4 & 56,025 \\
\hline 4 & 3.500 & 31.5 & 20,916 & 6.563 & 59.1 & 39,218 & 13.125 & 118.1 & 78,435 \\
\hline 5 & 4.500 & 40.5 & 26,892 & 8.438 & 75.9 & 50,423 & 16.875 & 151.9 & 100,845 \\
\hline 6 & 5.500 & 49.5 & 32,868 & 10.313 & 92.8 & 61,628 & 20.625 & 185.6 & 123,255 \\
\hline 7 & 6.500 & 58.5 & 38,844 & 12.188 & 109.7 & 72,833 & 24.375 & 219.4 & 145,665 \\
\hline 8 & 7.500 & 67.5 & 44,820 & 14.063 & 126.6 & 84,038 & 28.125 & 253.1 & 168,075 \\
\hline
\end{tabular}


Table 3 Mean undrained shear strength, adhesion factor and unit base and skin resistance for the pile lengths under examination

\begin{tabular}{lllllr}
\hline$L(\mathrm{~m})$ & $\sigma^{\prime}{ }_{\nu 0}(\mathrm{kPa})$ & $\begin{array}{l}c_{u}=0.83 \cdot \sigma^{\prime}{ }_{\nu 0} \alpha \\
(\mathrm{kPa})\end{array}$ & $p(\mathrm{kPa})$ & $s(\mathrm{kPa})$ \\
\hline 2 & 9 & 7.47 & 1.00 & 105.23 & 7.47 \\
3 & 13.5 & 11.205 & 1.00 & 157.845 & 11.21 \\
4 & 18 & 14.94 & 1.00 & 210.46 & 14.94 \\
5 & 22.5 & 18.675 & 1.00 & 263.075 & 18.68 \\
6 & 27 & 22.41 & 1.00 & 315.69 & 22.41 \\
7 & 31.5 & 26.145 & 0.99 & 368.305 & 25.81 \\
8 & 36 & 29.88 & 0.95 & 420.92 & 28.26 \\
9 & 40.5 & 33.615 & 0.90 & 473.535 & 30.40 \\
10 & 45 & 37.35 & 0.86 & 526.15 & 32.22 \\
11 & 49.5 & 41.085 & 0.82 & 578.765 & 33.74 \\
12 & 54 & 44.82 & 0.78 & 631.38 & 34.95 \\
13 & 58.5 & 48.555 & 0.74 & 683.995 & 35.85 \\
14 & 63 & 52.29 & 0.70 & 736.61 & 36.43 \\
15 & 67.5 & 56.025 & 0.66 & 789.225 & 36.71 \\
30 & 135 & 112.05 & 0.50 & 1578.45 & 56.03 \\
\hline
\end{tabular}

diameter is presented. In the FE model, the pile lateral surface is involved in the instability phenomenon thanks to the numerical interface; this means that in the numerical models the specific volume (defined as the ratio between the lateral surface and the base surface $\pi d L / \pi d^{2} L=1 / d$ ) introduces a nonlinear dependence of the critical load on the diameter.

In general, the aforementioned observations bring us to conclusion that piles of high slenderness and small diameters need particular attention in the definition of the ultimate load, normally related to the bearing capacity in the design. On the basis of pile slenderness, the critical load may be the main thing responsible for the failure mode and it should not be neglected in the design.

\section{Conclusions}

The use of piles of small diameters is nowadays one of the techniques available for soil reinforcement, generally used to solve excessive settlement problems and consequent structural damage. The lengths reached by this pile type are considerable (tens of metres), giving rise to very high slenderness (up to 300). Nevertheless, in practice their ultimate load is mostly related to the bearing capacity, calculated following the soil mechanics and foundation principles, without discussing the slenderness influence on their failure behaviour.
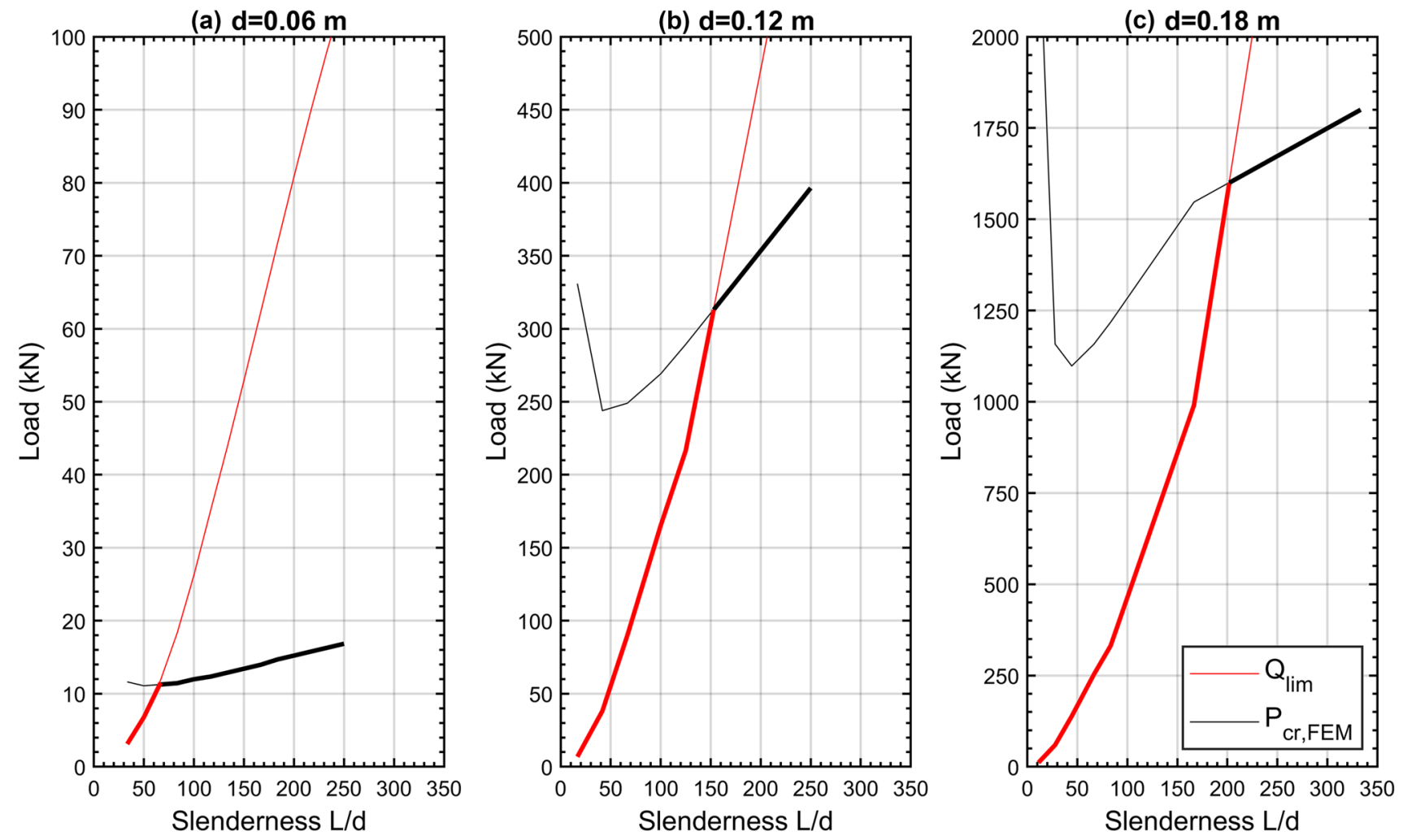

Fig. 6 Comparison of bearing capacity (red curve) and critical load from FEM analyses (black curve) for piles of diameter $0.06 \mathrm{~m}$ (a), $0.12 \mathrm{~m}$ (b) and $0.18 \mathrm{~m} \mathrm{(c)}$ 
(a)

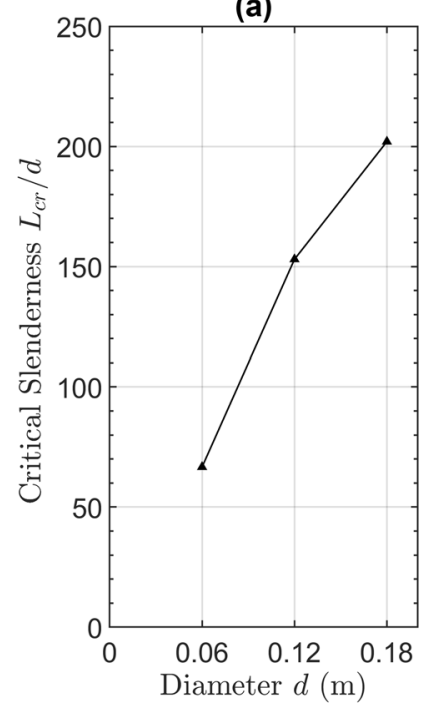

(b)

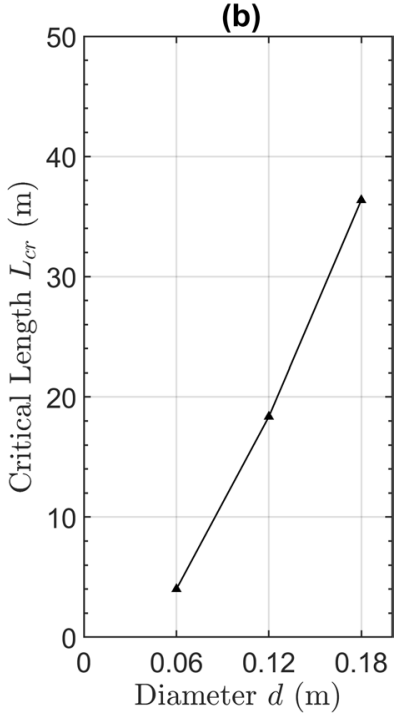

Fig. 7 Critical slenderness and lengths

The paper aimed to investigate whether the critical load, i.e. the buckling load of a pile embedded in the soil, can be less than the bearing capacity for certain slenderness, meaning that slenderness could affect the ultimate behaviour of these slender piles. For this purpose, a parametric analysis was conducted using a finite element numerical model to quantify the critical load; these results have been compared to the bearing capacity loads coming from classical formulations. The FE model accounted for the soil-pile interaction phenomenon, strongly affecting the evaluation of a critical load, through the modelling of a frictional contact; the model-dependent interface parameters were calibrated by numerically simulating the experimental load tests performed at the Geotechnical Centre of the Technical University of Munich by Vogt et al. The FE model demonstrated to capture the experimental critical load in a more than reasonable way. The parametric analysis conducted considering three diameter values and different pile lengths, giving rise to slenderness up to 300 , has brought us to the conclusion that:

- There are slenderness thresholds under which the ultimate behaviour is governed by the critical load and not the bearing capacity;

- The slenderness thresholds vary nonlinearly with diameters, due to the specific volume involved in the contact, which depends exclusively on diameter.

In general, high slenderness piles with a very small diameter therefore need particular attention in the evaluation of the ultimate load; the employment of the bearing capacity for design purposes should be restricted by observations on the buckling. Further studies will regard

the extension of the numerical analyses to different soil types and the realisation of further experimental tests to study real-scale slender piles.

Acknowledgments Open access funding provided by Università degli Studi di Parma within the CRUI-CARE Agreement.

Open Access This article is licensed under a Creative Commons Attribution 4.0 International License, which permits use, sharing, adaptation, distribution and reproduction in any medium or format, as long as you give appropriate credit to the original author(s) and the source, provide a link to the Creative Commons licence, and indicate if changes were made. The images or other third party material in this article are included in the article's Creative Commons licence, unless indicated otherwise in a credit line to the material. If material is not included in the article's Creative Commons licence and your intended use is not permitted by statutory regulation or exceeds the permitted use, you will need to obtain permission directly from the copyright holder. To view a copy of this licence, visit http://creativecommons.org/licenses/by/4.0/.

\section{References}

1. Nazir A, Azzam W (2010) Improving the bearing capacity of footing on soft clay with sand pile with/without skirts. Alex Eng J 49(4):371-377. https://doi.org/10.1016/j.aej.2010.06.002

2. Chow YK (1996) Settlement analysis of sand compaction pile. Soils Found 36(1):111-113. https://doi.org/10.3208/sandf.36.111

3. Abushar S, Han J (2001) Two-dimensional deep-seated slope stability analysis of embankments over stone column-improved soft clay. Eng Geol 120(1-4):103-110. https://doi.org/10.1016/j.engge o.2011.04.002

4. Bryson S, El Naggar H (2013) Evaluation of the efficiency of different ground improvement techniques. In: Proceedings of the 18th international conference on soil mechanics and geotechnical engineering: challenges and innovations in geotechnics (ICSMGE), Paris, vol 1, pp 683-686. https://www.cfms-sols.org/ sites/default/files/Actes/Volume1/20140319/assets/basic-html/ index.html\#1

5. Plumelle C (1984) Improvement of the bearing capacity of the soil by inserts of group and reticulated micropiles. In: International symposium on in-situ reinforcement of soils and rocks, Paris

6. Juran I, Bruce DA, Dimillio A, Benslimane A (1999) Micropiles: the state of practice. Part II: design of single micropiles and groups and networks of micropiles. Proc Inst Civ Eng Ground Improv 3:89-110. https://doi.org/10.1680/gi.1999.030301

7. Sridharan A, Srinivasa Murthy BR (1993) Remedial measures to a building settlement problem. In: Proceedings of the 3rd international conference on case histories in geotechnical engineering, Rolla, Missouri, vol 49, pp 221-224. https://scholarsmine.mst. edu/icchge/3icchge/3icchge-session01/49

8. Babu G, Murthy B, Murty D, Nataraj M (2004) Bearing capacity improvement using micropiles: a case study. Geotech Spec Publl. https://doi.org/10.1061/40713(2004)14

9. Han J, Ye S (2006) A field study on the behavior of micropiles in clay under compression or tension. Can Geotech J 43(1):19-29. https://doi.org/10.1139/t05-089

10. Mollaali M, Alitalesh M, Yazdani M, Shafie MB (2014) Soil improvement using micropiles. In: Proceedings of the 8th european conference on numerical methods in geotechnical engineering (NUMGE), Delft, vol 1, pp 535-540. https://doi.org/10.1201/ b17017-96 
11. Hwang TH, Kim KH, Shin JH (2017) Effective installation of micropiles to enhance bearing capacity of micropiled raft. Soils Found 57(1):36-49. https://doi.org/10.1016/j.sandf.2017.01.003

12. Mandel J (1936) Flambement au sein d'un milieu inelastique. Annales des Ponts et Chaussées, Deuxième Seminaire, Paris, pp 295-335

13. Cummings AE (1938) The stability of foundation piles against buckling under axial load. In: Proceedings of the 8th highway research board, Washington, vol 18, issue 2, pp 112-119

14. Glick GW (1948) Influence of soft ground on the design of long piles. In: Proceedings of the 2nd international conference on soil mechanics, Rotterdam, vol 4, pp 84-88

15. Johnsen LF, Gallagher MJ (2005) Proposed micropile section for the 2006 IB. In: Proceedings of the 30th annual conference on deep foundations, Chicago, pp 183-190

16. Shields D (2007) Buckling of micropiles. J Geotech Geoenviron Eng 133(3):334-337. https://doi.org/10.1061/ (ASCE)1090-0241(2007)133:3(334)

17. EN (European Standard) 1997-1 (1997) Eurocode 7- geotechnical design, European Committee for Standardization, Brussels

18. DIN (Deutsches Institut für Normung) 1054 (2005) Subsoil - verification of the safety of earthworks and foundations, Berlin, vol 8, issue 5, pp 1-2

19. Bjerrum L (1957) Norwegian experiences with steel piles to rock. Geotechnique 7(2):73-96. https://doi.org/10.1680/ geot.1957.7.2.73

20. Bergfelt A (1957) The axial and lateral load bearing capacity, and failure by buckling of piles in soft clay. In: Proceedings of the 4th international conference on soil mechanics and foundation engineering, London, vol 2, pp 8-13. https://www.issmge.org/uploa ds/publications/1/41/1957_02_0002.pdf

21. Davisson MT (1963) Estimating Buckling Loads for Piles. In: Proceedings of the 2nd Pan-American conference on soil mechanics and foundation engineering, Brazil, vol 2, pp 351-369

22. Prakash S (1987) Buckling loads of fully embedded vertical piles. Comput Geotech 4(2):61-83. https://doi.org/10.1016/0266352X(87)90011-5

23. Gabr MA, Wang J, Zhao M (1997) Buckling of piles with general power distribution of lateral subgrade reaction. J Geotech Geoenviron 123(2):123-130. https://doi.org/10.1061/ (ASCE)1090-0241(1997)123:2(123)

24. Heelis ME, Pavlović MN, West RP (2004) The analytical prediction of the buckling loads of fully and partially embedded piles. Geotechnique 54(6):363-373. https://doi.org/10.1680/ geot.2004.54.6.363

25. Mojdehi AR, Tavakol B, Royston W, Dillard DA, Holmes DP (2016) Buckling of elastic beams embedded in granular media. Extreme Mech Lett 9(1):237-244. https://doi.org/10.1016/j. eml.2016.03.022

26. Chen L, Chen YH, Shi JW, Chen G (2017) Buckling analysis of an axially loaded slender pile considering the promotion effect of soil pressure. Soil Mech Found Eng 54:161-168. https://doi. org/10.1007/s11204-017-9451-7

27. Lee JK, Jeong S, Kim Y (2018) Buckling of tapered friction piles in inhomogeneous soil. Comput Geotech 97:1-6. https://doi. org/10.1016/j.compgeo.2017.12.012

28. Salama MI, Basha AM (2019) Elastic buckling loads of partially embedded piles in cohesive soil. Innov Infrastruct Solut 4(12):18. https://doi.org/10.1007/s41062-019-0198-z

29. Mascardi CA (1982) Design criteria and performance of micropiles. In: Symposium on soil and rock improvement techniques including geotextiles, reinforced earth and modern piling methods, Bankok
30. Gouvenot D (1975) Essais de chargement et de flambement de pieux aiguilles. Annales de l'Institut Technique du Bâtiment et des Travaux Publics, Comité Français de la Mécanique des Sols et des Fondations, Paris, p 334

31. Vogt N, Vogt S, Kellner C (2005) Knicken von schlanken Pfählen in weichen Böden [Buckling of slender piles in soft soils]. Bautechnik 82:889-901. https://doi.org/10.1002/bate.200590252

32. Vogt N, Vogt S, Kellner C (2009) Buckling of slender piles in soft soils. Bautechnik 86:98-112. https://doi.org/10.1002/bate.20091 0046

33. Bathe KJ (1996) Finite element procedures. Prentice Hall, Pearson Education, Inc., Upper Saddle River

34. Kok ST, Huat BBK (2008) Numerical modeling of laterally loaded piles. Am J Appl Sci 5(10):1403-1408. https://doi.org/10.3844/ ajassp.2008.1403.1408

35. Balasubramaniam V (2018) A critical and comparative study on the 2D and 3D analyses of raft and piled raft foundations. Geotech Eng J SEAGS AGSSEA 49(1). ISSN 0046-5828

36. Bathe KJ, Bouzinov PA (1997) On the constraint function method for contact problems. Comput Struct 64(5-6):1069-1085. https:// doi.org/10.1016/S0045-7949(97)00036-9

37. Baziar MH, Rafiee F, Saeedi Azizkandi A, Lee CJ (2018) Effect of super-structure frequency on the seismic behavior of pile-raft foundation using physical modelling. Soil Dyn Earthq Eng 4:196209. https://doi.org/10.1061/(ASCE)GM.1943-5622.0001263

38. Baziar MH, Rafiee F, Lee CJ, Saeedi Azizkandi A (2018) Effect of superstructure on the dynamic response of nonconnected piled raft foundation using centrifuge modelling. Int J Geomech. https ://doi.org/10.1061/(ASCE)GM.1943-5622.0001263

39. Duncan JM, Buchignani AL (1976) An engineering manual for settlement studies. University of California, Bekeley

40. Davies J, Thompson P, Young S (2001) A comparison between tender, detailed design and field performance of diagrapham walls in Bankok. In: Geotechnical engineering - meeting society's needs: proceedings of the 14th Southeast Asian geotechnical conference, Hong Kong, vol 1, pp 291-296

41. Strozyk J, Tankiewicz M (2016) The elastic undrained modulus Eu50 for stiff consolidated clays related to the concept of stress history and normalized soil properties. Studia Geotech et Mech 38(3):67-72. https://doi.org/10.1515/sgem-2016-0025

42. Skempton AW (1959) Cast-in-situ bored piles in London clay. Geotechnique 9(4):153-173. https://doi.org/10.1680/ geot.1959.9.4.153

43. Wrana B (2015) Pile load capacity—calculation methods. Studia Geotech et Mech 37(4):83-93. https://doi.org/10.1515/ sgem-2015-0048

44. Doherty P, Gavin K (2011) The shaft capacity of displacement piles in clay: a state of the art review. Geotech Geol Eng 29:389410. https://doi.org/10.1007/s10706-010-9389-2

45. Saeedi Azizkandi A, Kashkooli A, Baziar MH (2014) Prediction of uplift pile displacement based on cone penetration tests (CPT). Geotech Geol Eng 32(4):1043-1052. https://doi.org/10.1007/ s10706-014-9779-y

46. Cherubini C, Vessia G (2008) Reliability approach for the side resistance of piles by means of the total stress analysis ( $\alpha$ method). Can Geotech J 44(11):1378-1390. https://doi.org/10.1139/ T07-061

47. American Petroleum Institute, API (1984) Recommended practice for planning designing and constructing fixed off-shore platforms. API, Washington 